\title{
RIEVISSIÓN
}

\section{Docosahexaenoic acid (DHA), an essential fatty acid for the proper functioning of neuronal cells: their role in mood disorders}

\author{
By Alfonso Valenzuela B
}

\author{
Centre of Lipids, INTA, University of Chile, PO Box 138-11, Santiago, Chile \\ (Corresponding author: avalenzu @ inta.cl)
}

\section{RESUMEN}

El acido docosahexaenoico (DHA), un acido graso esencial para la adecuada función de las células neuronales: su efecto en los desordenes del comportamiento.

El cerebro y el sistema nervioso son tejidos con un alto contenido de dos ácidos grasos poliinsaturados: el ácido araquidónico (20:4, omega-6, AA) y el ácido docosahexaenoico (22:6, omega-3, DHA). A pesar de la abundancia de estos ácidos grasos en dichos tejidos los mamíferos no los pueden sintetizar de novo. Sin embargo, la concentración de estos ácidos grasos puede ser modificada por la dieta. EI AA y el DHA pueden ser aportados por la dieta como tales (preformados) o a partir de los respectivos precursores de origen vegetal. El ácido linoleico, precursor del AA es muy abundante en la dieta occidental, por lo cual la formación de AA no es restrictiva. Por el contrario, el ácido alfa linolénico, cual es el precursor del DHA, es mucho menos disponible a partir de nuestra dieta, siendo muy restringido el consumo de este ácido graso en algunas poblaciones. El desarrollo del sistema nervioso ocurre de forma excepcionalmente rápida durante la última etapa del período gestacional y durante la primera etapa del período post natal. En estas etapas se requieren importantes cantidades de ácidos grasos poliinsaturados omega- 6 y omega-3, particularmente de DHA, ya que estos ácidos grasos son críticos para el crecimiento neuronal y para el desarrollo y función del cerebro y la retina. En esta revisión se analizan varias funciones del DHA en el sistema nervioso, su metabolismo en los fosfolípidos y su función en diferentes desordenes neurológicos y del comportamiento, tales como la enfermedad de Alzheimer, diferentes formas de depresión, y otras.

PALABRAS-CLAVE: Acido docosahexaenoico - Desordenes del comportamiento - Fosfolípidos cerebrales - Función neuronal.

\section{SUMMARY}

Docosahexaenoic acid (DHA), an essential fatty acid for the proper functioning of neuronal cells: their role in mood disorders.

The brain and the nervous system are tissues with high contents of two polyunsaturated fatty acids: arachidonic acid (20:4, omega-6, AA) and docosahexaenoic acid (22:6, omega-3, DHA). Despite their abundance in these tissues, $\mathrm{AA}$ and DHA cannot be re-synthesized in mammals. However, the concentration of these fatty acids can be modulated by dietary intake. AA and DHA must be provided by the diet as such (preformed) or through the respective omega- 6 and omega-3 precursors from vegetable origin. Linoleic acid, the precursor of $A A$ is very abundant in the western diet and therefore the formation of AA from linoleic acid is not restrictive. On the other hand, alpha linolenic acid, the precursor of DHA is less available in our diet and preformed DHA is highly restrictive in some populations. During the last period of gestation and during the early post natal period, neurodevelopment occurs exceptionally quickly, and significant amounts of omega- 6 and omega- 3 polyunsaturated fatty acids, especially $\mathrm{DHA}$, are critical to allow neurite outgrowth and the proper brain and retina development and function. In this review various functions of DHA in the nervous system, its metabolism into phospholipids, and its involvement in different neurological and mood disorders, such as Alzheimer's disease, depression, and others are revised.

KEY-WORDS: Brain phospholipids - Docosahexaenoic acid - Mood disorders - Neural function.

\section{INTRODUCTION}

During the last trimester of intrauterine foetal life and the first 2 years of childhood, the brain undergoes a period of rapid growth and development which has been defined as the "brain growth spurt" (McCann \& Ames, 2005). Research over the last 30 years has established that long-chain omega-6 and omega-3 polyunsaturated fatty acids (LC-PUFAs) are critical for the development and functioning of the brain and nervous system and for the proper growth and development of newborns and children (Uauy \& Valenzuela, 2000; Wainwright, 2002; Valenzuela et al., 2006). Brain growth spurt is associated with a rapid increase in the incorporation of LC-PUFAs into phospholipids that form the brain cortex. The brain and nervous system, the retina and the sperm have the highest concentration of the omega-3 LC-PUFA docosahexaenoic acid (22:6, DHA), the most highly polyunsaturated fatty acid found in mammals. In the retina, a tissue, which from the phylogenetic point of view can be considered of neural origin (Jeffrey et al., 2001), DHA, is concentrated in the outer segments of photoreceptors, in which nearly $50 \%$ of the fatty acid 
is associated with the phospholipids of these cells (Fliesler \& Anderson, 1983). In neurons, DHA is mainly associated with membrane phospholipids where they affect membrane fluidity and regulate the function of many functional membrane-associated proteins (Rapoport, 2001). DHA, when liberated from membrane phospholipids by specific phospholipases, may act as a regulatory molecule, as nuclear receptor ligand or can be converted into other signalling molecules, collectively known as docosanoids such as docosatrienes, and the tri-hydroxy-containing autacoids resolvins (Hong et al., 2003; Serhan \& Chiang, 2004). This conversion occurs not in neuronal cells but in brain glial cells (Hong et al., 2003). The novel endogenous DHA-derived 10, 17 Sdocosatriene, formed via a 15-lipooxygenase-like enzyme and identified as neuroprotectin D1, is a potent regulator of an intrinsic neuroprotective, antiinflammatory and antiapoptotic gene-expression program that promotes survival in a stressed human brain (Lukiw et al., 2005; Lukiw \& Bazan, 2006).

It is well known that a nutritional deficiency in omega- 6 essential fatty acids in humans may results in several pathological abnormalities such as reduced growth, skin lesion, fatty liver, and reproductive failure (Holman, 1998). However, neuronal functioning appears not to be affected by nutritional omega- 6 fatty acid deficiency. On the other hand, a nutritional deficiency in omega-3 fatty acids results in several neuronal specific effects such as reduced learning capacity, memory impairment, abnormal electroretinogram, impaired vision and numbness (Connor et al., 1992; Benatti et al., 2004). The different pathological defects that occur with either omega- 6 or omega-3 fatty acid deficiency demonstrated that these two types of fatty acids are not metabolically interchangeable; omega- 6 cannot substitute omega- 3 fatty acids or vice-versa. Mammals cannot transform omega- 6 fatty acids into omega-3 fatty acids (Kang, 2005). Most of the experimental research about omega6/omega-3 fatty acid deficiency has been focussed on the consequences of omega-3 deficiency, because omega- 6 deficiency in humans is extremely rare. The western diet provides sufficient amounts of omega- 6 fatty acids but very low amounts of omega-3 fatty acids (Simopoulos, 2002) because preformed DHA is scarce in some populations.

\section{DHA IN THE BRAIN AND NERVOUS SYSTEM}

Within neurons, DHA is highly concentrated in membrane phospholipids, mainly as phosphatidylethanolamine and phosphatidylserine, the latter being the major acidic phospholipid in brain cell membranes (Breckenridge et al., 1972). Phospholipids which make up about one quarter of the solid matter in the brain are also an integral part of the vascular system on which brain function and nutrition depend. DHA makes up $15-20 \%$ of the fatty acid composition of the brain cortex, and when incorporated into phospholipids may improve the efficiency of synaptic membrane vesicles in fusion events which are fundamental for neurotransmission (Salem et al., 2001). DHA may also function in synaptic signalling either as a free fatty acid, as a metabolite or incorporated into phospholipids. DHA is also highly concentrated in growth cones during neurite outgrowth where it may be important for maximal neurite growth during brain development which occurs mainly during the perinatal period (Martin \& Bazan, 1992). In the adult, DHA is found in neuronal dendrites, where it may be involved in the extension and establishment of the dendritic arborization which occurs during memory formation and the acquisition of learning capacities, modifications which originate in brain plasticity. Additionally, DHA may be important for the efficient regeneration of axons and dendrites in some brain regions, such as the cerebellum and hippocampus, after neuronal injury. Supplementing cultured neuronal cell types with $\mathrm{AA}$ and DHA at low concentrations significantly increases neurite outgrowth in several neuronal cell types, principally those from hippocampus (Calderon \& Kim, 2004). However, there is a limit to the amount of AA to be added because at higher concentrations this fatty acid is cytotoxic. DHA, however, shows stimulant effects and no cytotoxicity in a wide range of concentrations (Ikemoto et al., 1997).

\subsection{The role of DHA in neuronal phospholipid synthesis}

DHA appears to enhance neurite outgrowth by several mechanisms which include an increase in the synthesis of specific phospholipids (Calderon \& Kim, 2004). In differentiating and mature neurons DHA is preferentially incorporated into phospholipids rather than into triglycerides. During the synthesis of neuronal phospholipids, DHA is acylated to the sn-2 position of phospholipids to generate phosphatidic acid, which is the precursor of phosphatidylinositol. However, most of the phosphatidic acid is subsequently dephosphorylated to generate diacylgycerol, which is further metabolized into phosphaditidylcholine, phosphatidylethanolamine, phosphatidylserine and triglycerides, all of these molecules containing DHA specifically at the sn-2 position (Calderon \& Kim, 2004). Therefore, it appears that diacylglycerols containing DHA at the sn-2 position are preferentially transformed into phospholipids. This specific transformation occurs through the action of specific enzymes. For example, diacylglycerol molecules that contain DHA in the sn2 position are the preferred substrate of enzyme ethanolamine phosphotransferase which converts diacylglycerol to phosphatidylethanolamine through the covalent linking of ethanolamine to the sn-3 position of diacylglycerol (Holub, 1978). Subsequently, phosphatidylethanolamine can be converted to phosphatidylserine through the exchange of the nitrogen base with free serine (Mozzi et al., 2003). 
Every cell type typically maintains a constant ratio of phospholipid species and a change in one species of phospholipids into another may often alter the level of another species (Araki \& Wurtman, 1998). In neurons, the bulk of DHA is incorporated into phosphatidylethanolamine and to a lesser extent to phosphatidylserine. On the other hand, the majority of $A A$ is incorporated into phosphatidylinositol and phosphatidylethanolamine. The bulk of other unsaturated fatty acids, such as oleic acid, is incorporated mainly into phosphatidylinositol. The differential incorporation of AA and DHA into phosphatidylinositol, phosphatidylserine and phosphatidylethanolamine, compared with phosphatidylcholine, may make an important contribution to their specific functions in neurons. The exact mode of action of DHA-containing phospholipids in brain functions is at present not known but there might be a relationship between their effect on the blood-brain barrier, membrane structure and fluidity in the activity of some specific enzymes, neural signalling, ionic channel permeability or the formation and control of nerve growth factors (Kitajka et al., 2002). All these effects may be involved in the brain's cognitive functions such as memory and learning.

\subsection{The role of DHA in membrane neuronal function}

The quantity of double bonds in a fatty acid is directly related to the flexibility of the molecule. Saturated fatty acids, such as palmitic acid (16:0) or stearic acid (18:0), are rigid. This rigidity allows saturated fatty acids to pack together tightly and form a solid structure at lower temperatures. Phospholipids formed by these fatty acids are also rigid structures. The introduction of double bonds into a fatty acid causes a "kink" in its structure which modifies its spatial conformation. DHA, which has six double bonds, may adopt many countless conformations because the molecule can rotate around $\mathrm{C}-\mathrm{C}$ bonds but not around the rigid six $\mathrm{C}=\mathrm{C}$ that conform its high polyunsaturation (Feller et al., 2002). The highly flexible structure of DHA will not allow phospholipids containing DHA to pack tightly together, resulting in a significant increase in membrane fluidity relative to phospholipids formed only by saturated fatty acids. Membranes having high contents of DHA may also increase the efficiency of membrane fusion events which are important in neurotransmission (Teague et al., 2002). Additionally, an increased fluidity of membranes appears to be important for increasing the rate at which membrane protein-protein interaction occurs within the phospholipid's membrane bilayer. Fluidity is especially relevant in the outer segments of retinal photoreceptors where the activation of $\mathrm{G}$ type protein transducin by the rhodopsin-metarhodopsin interaction events occurs within the phospholipids of photoreceptor cells. This process does not occur efficiently when the level of DHA in the phospholipids of vision cells is reduced either during normal ageing or by pathological causes (Niu et al., 2004). Mitochondrial phospholipids are also enriched in DHA. High DHA in mitochondrial membranes may increase the efficiency of the electron transport chain and the ADP-phosphorilation process by increasing the lateral movement of proteins within the membrane bilayer, thus facilitating protein-protein interactions (Valentine \& Valentine, 2004). Additionally, there is a direct correlation between the DHA content of mitochondrial phospholipids and the permeability of the inner membrane to protons (Hulbert, 2003), thus improving the efficiency of energy production through oxidative phosphorilation. It is generally concluded that DHA positively influences mitochondrial energy function.

\subsection{DHA and the activity of neuronal enzymes}

Receptor functioning and the activation of proteins involved in neuronal signalling transduction can be influenced by DHA, either as a free fatty acid and/or when it is incorporated into membrane phospholipids. DHA is concentrated in the phospholipids of neural tissues, including the hippocampus (Ahmad et al., 2002) which is involved in learning as well as in memory storage. Recently, we demonstrated that DHA supplementation to mother rats during the perinatal period, increases the DHA content of different brain segments of the pups, including hippocampus, and improves the learning and memory capacities of the pups when evaluated through the Skinner box test (Valenzuela et al., 2008). As part of the diacylglycerol molecule, DHA enhances the diacylglycerol-dependent activation of the protein kinase C (PKC) (Chen \& Murakami, 1994). It is interesting that PKC has an essential requirement for phosphatidylserine (Nishizuka, 1995), which contains a high concentration of DHA. However, in vitro evidence is suggesting that unesterified DHA may competitively inhibit phosphatidylserine dependent PKC activation. Unesterified AA either stimulates or has no effect on PKC activity (Seung Kim et al., 2001), showing that activation of the enzyme by omega-3 fatty acids may be specific to these fatty acids. Another example of a protein whose function is modified by DHA is $\mathrm{Na}+$, $\mathrm{K}+$ ATPase, also known as sodium pump, which is an integral protein of the neuronal membrane found in higher concentration at the axonal nodes of Ranvier. The primary neuronal function of this ATPase is to generate and maintain $\mathrm{Na}+$ and $\mathrm{K}+$ gradients necessary to maintain the resting potential of neuronal membrane. The activity of $\mathrm{Na}+-\mathrm{K}+$ ATPase is increased in the sciatic nerve of rats that are supplemented with DHA (Gerbi et al., 1998).

\subsection{Inhibition of neuronal apoptosis by DHA}

Neuronal cell survival is highly dependent on the presence of trophic nerve factors which influence downstream signalling pathways. Modifications in the 
concentration and/or number of these factors may lead to apoptotic cell death. Early signs of apoptosis include the loss of intracellular water, an increase in cytoplasmic calcium concentration, the releasing of cytochrome $\mathrm{c}$ from mitochondria and the translocation of phosphatidylserine to the outer leaflet of the plasma membrane (Sastry \& Rao, 2000). The activation of the caspase-3 enzyme by self-cleavage results in the death of cells by apoptosis (Nagata, 1997). The prevention of apoptosis by DHA incorporation into phospholipids has been reported for rat retinal photoreceptors (Rotstein et al., 1997), HL-60 cells (Kishida et al., 998), and Neuro 2A cells (Kim et al., 2000). Additionally, an increased dietary intake of DHA prevents apoptosis in mouse retinal photoreceptors when subjected to N-methyl-Nnitrosourea, a potent inducer of apoptosis (Moriguchi et al., 2003). DHA accumulation in phospholipids, mainly in phosphatidylserine, appears to promote neuronal survival under adverse conditions (Kim et al., 2000).

As discussed above, in the nervous system, DHA is incorporated primarily into anionic phospholipids such as phosphatidylserine and phosphatidylethanolamine (Aid et al., 2003). Phosphatidylserine is synthesized from phosphatidylethanolamine or phosphatidylcholine by the serine replacement of ethanolamine or choline, respectively, in a base-exchange reaction. Phosphatidylserine is involved in a series of cellsignaling events. The supplementation of cells with unesterified DHA promotes phosphatidylserine biosynthesis (Kim \& Hamilton, 2000). The enrichment of DHA in phosphatidylserine and its effect on phosphatidylserine biosynthesis are most likely due to the fact that phospholipid species containing DHA are the best substrates for phosphatidylserine synthesizing enzymes (Kim et al., 2004). There is not a direct correlation between the level of phosphatidylserine and DHA content in different brain segments. The antiapoptotic effect of DHA in neurons occurs only when the fatty acid is added to cultured cells or when experimental animals have been treated previously with DHA, which may suggest that these effects are due to the incorporation of DHA into different phospholipids. It is interesting to note that in other non-neuronal cell types, DHA actually promotes apoptosis. For example, in CaCo-2 cells, a colon cancer cell line, DHA induces apoptosis by "downregulating" reducing the expression of antiapoptotic genes and increasing the expression of proapoptotic genes (Narayanan et al., 2001). Therefore, the antiapoptotic effects of DHA-containing phosphatidylserine are probably specific to neuronal cells and critical for the long-term survival of these cells.

\subsection{DHA and the regulation of gene expression in neurons}

It has been demonstrated that polyunsaturated omega-3 fatty acids can modify gene expression by binding to specific receptors and transcription factors in the liver and adipose tissue. Receptors activated by DHA include retinoid $X$, peroxisome proliferator activated receptors (PPARs), hepatic nuclear receptor, and sterol regulatory element binding protein (SREBP) receptor (Mata de Urquiza et al., 2000). The activation of each of these proteins modulates the expression of genes involved in the metabolism of glucose, fatty acid, triglyceride, and cholesterol. Of these proteins, the retinoid $X$ receptor is present in significant levels in the brain, and DHA is an effective ligand and activator of the retinoid $X$ receptor protein (Lengqvist et al., 2004). Activation of gene expression by DHA is not restricted to brain cells, the fatty acid activates several genes in other tissues, like liver or adipose tissue (Kitajka et al., 2002). In rat brain cells, the stimulation of peroxisomal proliferator activated receptor $\beta$ (PPAR $\beta$ ) and resulted in the upregulation of the mRNA encoding a protein that converted DHA to the acylCoA derivative (Marszalek et al., 2005). Upon alteration of the expression of genes involved in lipid metabolism, the optimal environment for neurite outgrowth can be achieved during neuronal differentiation and brain formation. For example, omega- 6 and omega-3 PUFAs have been shown to decrease the expression and the activity of $\Delta-9$ desaturase, the enzyme that converts estearic acid (18:0) to oleic acid (18:1, omega-9) (Sessler et al., 1996). This effect may be important to ensure that saturated fatty acids, whether newly synthesized or taken in from the diet, are available for the insertion of phospholipids into the sn-1 position as they are synthesized. Several studies have demonstrated that the DHA increasing effect on neurite outgrowth may be, in part, a consequence of the DHA stimulation of the expression of genes that promote phospholipids synthesis (Barcelo-Coblijn, 2003; Puskas et al., 2003). Using microarray gene expression methodology, it has been demonstrated that fish oil or DHA supplementation can modify the expression of many of the genes of the brain and retina involved in signal transduction, eicosanoid production, synaptic plasticity, and energy metabolism in rats (Rojas et al., 2003).

\section{DHA AND ALTERATIONS OF NEURONAL FUNCTIONING AND MOOD DISORDERS}

During periods of nutritional deficiency of omega-3 fatty acid, DHA is retained to depletion from the phospholipids of neurons through at least two different mechanisms. First, DHA released from membrane phospholipids is rapidly reacylated to specific phospholipids. Second, there is a significant reduction in the rate of transfer of DHA out of the nervous system through the blood-brainbarrier. Many neurodegenerative conditions, such as Alzheimer's disease, retinal affections, and some peroxisomal disorders (Zellweger syndrome and adrenoleucodisthrophy) are associated with 
reduced levels of omega-3 fatty acids. Mood disorders, such as depression, schizophrenia, and post partum depression, have also been associated with modifications in DHA metabolism. Epidemiological, experimental and clinical data favour the hypothesis that DHA could play a role in the pathogenesis and eventually in the treatment of these diseases (Parker et al., 2006; Stahl et al., 2008).

\subsection{Alzheimer's disease}

Alzheimer's disease is a late-onset, progressive, neurodegenerative disease of heterogeneous origin which is devastating both to the afflicted person and to that person's family. The pathology is characterized by the formation of amyloid plaques, neurofibrillary tangles, and dystrophic neurites. Data from numerous epidemiological studies suggest an inverse correlation between DHA intake and the likelihood of developing Alzheimer's disease. A reduction in the level of total phospholipids as well as a decrease in DHA has been described in various cerebral areas in Alzheimer's disease patients (Prasad et al., 1998). Studies have demonstrated that the levels of phosphatidylethanolamine, which is enriched in $\mathrm{DHA}$, and of phosphatidylinositol, which is enriched in $A A$, are significantly reduced in the brain of individuals affected by Alzheimer's disease. Specifically, there is a significant reduction in the amount of DHA in the frontal cortex and hippocampus phospholipids of patients with Alzheimer's disesase (Soderberg et al., 1991). The pretreatment of rats with DHA protected the animals against the memory loss which typically occurs when they are infused with Alzheimer disease $A \beta$ peptide, which triggers a synapse loss (Coleman \& Yao, 2003). DHA inhibits the accumulation of insoluble $A \beta$ peptide, partially by decreasing cholesterol levels in the detergent insoluble membrane domains (rafts) of the cerebral cortex (Hashimoto et al., 2005). It has been recently demonstrated that the effect of DHA in the reduction of insoluble $A \beta$ peptide is attributable to a decrease in the steady-state levels of presenilin 1 (Green, et al., 2007). In cognitive tests, animals expressing high levels of a mutant amyloid precursor protein, showed low levels of DHA in brain phospholipids. Additionally, the activity of phospholipase A2, which is involved in the liberation of AA from brain phospholipids, increases in the brain of patients with Alzheimer's disease, suggesting that an increased generation of AAderived eicosanoids, which are antagonist of DHAderived docosanoids, may contribute to the aetiology of Alzheimer's disease. It has been proposed that DHA-derived neuroprotectin induces an antiapoptotic and neuroprotective geneexpression program that regulates the secretion of $A \beta$ peptide, resulting in the modulation of inflammatory signalling, neuronal survival, and the preservation of brain cell function (Lukiw et al.,
$2005)$. The typical Western diet provides $<30 \%$ of the $200-300 \mathrm{mg} /$ day of DHA recommended by Expert Panels. Epidemiology shows a risk reduction of $60 \%$ associated with a modest increase in DHA intake or plasma levels. DHA works well in slowing down Alzheimer's disease pathogenesis in mice with a human Alzheimer's disease gene (Calon et al., 2004). DHA provided by supplementation (e.g. fish meals, fish oil capsules, or other forms of DHA supplementation), could restore DHA deficiency in membrane phospholipids in the cerebral cortex of patients with Alzheimer's disease (Connor \& Connor, 2007). DHA, together with natural antioxidants, may exert general anti-Alzheimer's and anti-aging benefits (Cole et al., 2005).

\subsection{Depression and postpartum depression}

Depression is a complex disorder that particularly involves neurotransmission processes, especially serotonin receptors and membrane transporters (Meltzer, 1990). The aetiology of the illness is multi factorial, influenced by genetic, environmental, and nutritional factors. Support for a nutritional contribution to the disease derives from studies that report an inverse correlation between the level of omega-3 fatty acids (DHA and/or EPA), as measured in either red blood cell phospholipids or adipose tissue, and symptoms of depression (Freeman et al., 2006). An increased ratio of omega-6/omega-3 is frequently observed in patients suffering from depression (Peet et al., 1998; Haag, 2003). Numerous studies carried out over the last few years are involving omega-3 LCPUFA supplementation with the reduction of many of the symptoms of different forms of depression, including bipolar disorders, postpartum depression (discussed forward), agoraphobia, and anorexia nervosa (Locke \& Stoll, 2001; Logan, 2004). EPA supplementation appears to be more effective than DHA supplementation in reducing the symptoms of depression as concluded from a recent metaanalysis (Lin \& Su, 2007). Depression and coronary artery disease often occur in the same individuals who frequently have low plasma levels of EPA and DHA and high levels of AA. Omega-3 LC-PUFA supplementation is effective in the prevention of these pathological disorders (Frasure-Smith et al., 2004; Astog et al., 2008). However, the mechanism(s) by which EPA and/or DHA may reduce depression are still unclear, and more research is needed. As discussed, increasing the nutritional levels of omega-3 fatty acids may modify the activity of integral membrane proteins (receptors, ion channel, molecular pups, etc), and/or counteract the proinflammatory action of AAderived eicosanoids.

Depression during pregnancy and postpartum depression have negative impacts on the development and health of the newborn. Maternal stress in humans is associated with foetal hypoxia, reduced gestational age, and low birth weight (Wadhwa et al., 1993). Evans et al (2001) found that 
$13.5 \%$ of women $(n=14,541)$ experienced serious symptoms of depression during pregnancy and postpartum. A cross-national analysis of seafood consumption, and the DHA content of breast milk, demonstrated an inverse correlation with the prevalence of pregnancy and postpartum depression. The prevalence varied from $0.5 \%$ in Singapore to $24.5 \%$ in South Africa, with a mean prevalence rate worldwide of $12.4 \%$. Both higher national seafood consumption and higher DHA content in the mother's breast milk predicted a lower prevalence of postpartum depression. The mean DHA intake of western women is estimated at 15-20 $\mathrm{mg} /$ day, whereas intake in countries with high fish consumption (e.g. Japan, Korea, and Norway) is approximately $1000 \mathrm{mg} /$ day. During the third gestational trimester, the foetus accumulates an average of $67 \mathrm{mg} /$ day of $\mathrm{DHA}$, in excess of the dietary intake of many women. Such transfer to the baby through the placenta and, subsequently through breast milk poses a risk to women of significant depletion of omega-3 fatty acids during pregnancy and lactation, thus contributing to the perinatal risk of depression. A review by Parker et al., (2006) about omega-3 fatty acids and postpartum depression, proposed that DHA supplementation in the perinatal period may have additional benefits for the infant's neurodevelopment. Women and their physicians prefer options to standard antidepressant medication during pregnancy and postpartum. DHA supplementation during these periods may be a plausible alternative (Freeman et al., 2006). However, more clinical trials are needed to confirm the recommendation of omega-3 fatty acid supplementation to avoid or reduce symptoms of depression.

\subsection{Schizophrenia}

Schizophrenia is a psychiatric disease that affects $\sim 1 \%$ of the population with a higher prevalence in males than in females. The predominant hypothesis regarding the pathophysiology of the disease is dysfunction of the dopaminergic system. However, further findings concerning the disease suggested a close relationship with reduced tissue levels of omega- 6 and omega-3 fatty specially $\mathrm{AA}$ and DHA (Yao et al., 2000). Several mechanisms could explain these deficits, including an increased activity of phospholipase $\mathrm{A} 2$ thus inducing the extraction of AA and DHA from cerebral membranes (Horrobin et al., 1994). Another argument in favour of a relationship between schizophrenia and omega6/omega-3 fatty acids is that dietary supplementation of either AA and DHA or their precursors is able to alleviate symptoms of the disease (Arvindakshan et al., 2003). It has been recently proposed that an alteration of $\mathrm{DHA}$ metabolism in the brain is involved in the pathophysiology of schizophrenia and that omega3 fatty acid supplementation may be an important coadjutant in the treatment of the disease (Kale et al., 2008). It seems therefore that schizophrenia might be an example of a disease in which omega6 and omega-3 supplementation, presumably AA and DHA, associated with pharmacological treatment might be beneficial, although extended evaluation of such treatment is still required (Fenton et al., 2000).

\subsection{Retinal function}

Retinal pathologies are not directly involved with mood disorders. However, the retina has neural origin and DHA is essential for the proper development and functioning of this tissue, particularly at the outer membrane segments of photoreceptors cells. DHA is required for the survival of retinal photoreceptors and exerts a protective effect on apoptosis of these photoreceptors during development (Kim et al., 2000). Retinitis pigmentosa is a visual disease with a worldwide prevalence of about 1 in 4000 persons (Boughman et al., 1980). A correlation between retinitis pigmentosa and low retinal DHA levels has been observed, were there is some evidence that the synthesis of DHA is impaired in patients suffering from $X$-linked retinitis pigmentosa (Kim et al, 2000). Supplementation with DHA (400 mg/day) for four years produced a significant a reduction in the loss of the functionality of rods in patients with retinitis pigmentosa, as assessed by an electroretinogram which measures photoreceptor functioning. For patients with retinitis pigmentosa beginning vitamin A therapy, along with DHA (1200 $\mathrm{mg} /$ day) slowed the course of the decline in visual field sensitivity (Berson et al., 2004). These results suggest that early intervention with omega-3 fatty acids, presumably with DHA, may be important in slowing down the progression of retinitis pigmentosa.

\section{POSSIBLE MECHANISMS FOR LINKS BETWEEN DHA AND MOOD DISORDERS}

Several neurophysiological mechanisms have been proposed to explain the relationship between omega-3 polyunsaturated fatty acids and mood disorders (Mamalakis et al., 2002). EPA and DHA appear to decrease the production of inflammatory eicosanoids from AA by means of two mechanisms: First, they compete with AA for incorporation into membrane phospholipids, thus decreasing both cellular and plasma levels of AA. Second, EPA and presumably DHA compete with AA for the cyclooxygenase enzyme system, inhibiting the production of proinflammatory eicosanoids derived from AA (e.g. prostaglandins, leukotrienes, hromboxanes). Prostaglandin E2 and thromboxane B2 have been linked to depression. DHA also inhibits the release of proinflammatory cytokines such as interleukin-1 beta, interleukin-2, interleukin6 , interferon gamma, and tumor necrosis factor 
alpha which depends on eicosanoid release and are also associated with mood disorders, such as depression (Logan, 2003). Another possible mechanism relates to the abundance of DHA in brain phospholipids were they play a vital role in maintaining the integrity and fluidity of neuronal membranes. By varying the lipid concentration in cell membranes, changes in fluidity can affect either the structure or functioning of proteins embedded in the membrane, including enzymes, receptors or ion channels, leading to changes in cellular signalling (Yehuda et al., 1998; Stahl et al., 2008). Support for the involvement of DHA in receptor functioning, neurotransmitter levels and the metabolism of monoamines implicated in mood disorders has been provided by animal studies (Hibbeln \& Salem, 1995).

The hypothesis that DHA can affect membrane fluidity is supported by a recent study using magnetic resonance imaging (Hirashima et al., 2004). A group of bipolar women received DHA for 4 weeks and were contrasted with a non treated bipolar group. $T_{2}$ whole relaxation times were used to detect changes in membrane fluidity, measured at baseline and 4 weeks after omega-3 fatty acid treatment. The bipolar patients receiving DHA treatment showed significantly decreased $T_{2}$ values, with a dose-dependent effect compared to the control group. Another hypothesis involves a more direct mechanism controlling gene expression and the binding of fatty acids to specific nuclear receptors early in life, as was discussed above, leading to genetic transcription and predisposure to a range of diseases related to DHA depletion later in life, such as Alzheimer's disease, cardiac disease, and depression (Sampath \& Ntambi, 2004).

\section{CONCLUSIONS AND FUTURE PROSPECTS}

A significantly amount of references clearly establish that DHA is important for the proper neurodevelopment of the brain and visual system. Epidemiological evidence suggest that a decrease in brain DHA levels, which normally occurs during aging, and that is exacerbated by reduced dietary intake of DHA, may increase the prevalence of several neurological diseases, such as Alzheimer's disease. However, at present we do not understood at all the complex functions that DHA performs as either a free fatty acid or incorporated into phospholipids. Further research is needed to better understand the process of DHA transport, internalization and membrane inclusion, as well as DHA metabolism into its incorporation into phospholipids. The identification of several DHAderived metabolites, probably involved in cell signalling suggests that free DHA is utilized to perform many functions beyond a structural role in phospholipids and membrane structure. Future research about food and/or additives that preferentially provide DHA and molecules that promote its internalization, transport and metabolism is clearly needed to fully understand the importance of DHA in the development, normal function, senescence, and pathology of the nervous system. Establishing the functions of DHA in the nervous system will be critical to appreciating the possible health implications of a reduced dietary intake of DHA currently occurring in western populations, and the importance of DHA supplementation, at the early and late stages of human life. Basic, clinical and epidemiologic research supports a protective effect of omega-3 LC-PUFA, particularly of DHA in mood disorders. However, results are highly heterogeneous and in some cases confounding, indicating that it is important to examine the results of each individual study in order to anticipate more general conclusions about the role of DHA in the brain and nervous system and in mood disorders.

\section{ACKNOWLEDGMENTS}

The research of the author has been supported by FONDECYT, FONDEF and INNOVA-CORFO.

\section{REFERENCES}

Ahmad A, Moriguchi T, Salem N. 2002. Decrease in neuron size in docosahexaenoic acid-deficient brain. Pediatr. Neurol. 26, 210-218.

Aid S, Vancassel S, Poumes-Ballihaut C, Chalon S, Guesnet P, Lavialle M. 2003. Effect of a diet-induced $n-3$ PUFA depletion on cholinergic parameters $n$ the rat hippocampus. J. Lipid Res. 44, 1545-1551.

Araki W, Wurtman R J. 1998. How is membrane phospholipids biosynthesis controlled in neural tissues? J. Neurosci. Res. 51, 667-674.

Arvindakshan M, Ghate M, Ranjekar P, Evans D, Mahadik SP. 2003. Supplementation with a combination of omega-3 fatty acids and antioxidants (vitamin E and C) improves the outcome of schizophrenia. Schizophr. Res. 62, 195-204.

Astorg P, Curtois A, Bertrais S, Arnault N, Meneton P, Guesnet P, Alessandri J M, Galan P, Hercberg S. 2008. Association of fish oil and long-chain $n-3$ polyunsaturated fatty acid intakes with the occurrence of depressive episodes in middle-aged French man and women. Prostaglandin Leukot. Essent. Fatty Acids 78, 171-182.

Barcelo-Coblijn G, Hogyes E, Kitajka K, Puskas L G, Zvara A. 2003. Modification by docosahexaenoic acid of age-induced alterations in gene expression and molecular composition of rat brain phospholipids. Proc. Natl. Acad. Sci. USA. 100, 11321-11326.

Benatti P, Peluso G, Nicolai R, Calvani M. 2004. Polyunsaturated fatty acids: biochemical, nutricional and epigenetic properties. J. Am. Col. Nutr. 23, 281302.

Berson EL, Rosner B, Sandberg M, Weigel-DiFranco C, Moser A, Brockhurst R, Hayes K, Johnson C, Anderson E, Gaudio A, Willett W, Schaefer E. 2004. 
Further evaluation of docosahexaenoic acid in patients with retinitis pigmentosa receiving vitamin $A$ treatment. Arch. Ophthamol. 122, 1306-1314.

Bougham JA, Conneally PM, Nance WE. 1980. Population genetic studies of retinitis pigmentosa. Am. J. Hum. Genet. 32, 223-235.

Breckenridge W C, Gombos G, Morgan IG. 1972. The lipid composition of adult rat brain synaptosomal plasma membranes. Biochim. Biophys. Acta 266, 695-707.

Calderon F, Kim HY. 2004. Docosahexaenoic acid promotes neurite growth in hippocampal neurons. $J$. Neurochem. 90, 979-988.

Calon F, Lim GP, Yang F, Morihara T, Teter B, Ubeda O. 2004. Docosahexaenoic acid protects from dendritic pathology in an Alzheimer's disease mouse model. Neuron 43, 47-55.

Chen SG, Murakami K. 1994. Effects of cis-fatty acid on protein kinase $\mathrm{C}$ activation and protein phosphorilation in the hippocampus. J. Pharm. Sci. Technol. 48, 71-75.

Cole GM, Lim GP, Yang F, Teter B, Begum A, Ma Q, Harris-White M E, Frautschy S A. 2005. Prevention of Alzheimer's disease: omega-3 fatty acid and phenolic anti-oxidant interventions. Neurobiol. Aging 26S, S133-S136.

Coleman P D, Yao PJ. 2003. Synaptic slaughter in Alzheimer's disease. Neurobiol. Aging 24, 10231027.

Connor WE, Neuringer M, Reisbick S. 1992. Essential fatty acids; the importance of $n-3$ fatty acids in the retina and brain. Nutr. Rev. 50, 21-29.

Connor WE, Connor JL. 2007. The importance of fish and docosahexaenoic acid in Alzheimer's disease. Am. J. Clin. Nutr. 85, 929-930.

Evans J, Heron J, Francomb H, Oke S, Golding J. 2001. Cohort study of depressed mood during pregnancy and after childbirth. Brit. Med. J. 323, 257-260.

Feller S E, Gawrisch K, MacKerell AD. 2002. Polyunsaturated fatty acids in lipid bilayers: intrinsic and environmental contributions to their unique physical properties. J. Am. Chem. Soc. 124, 318-326.

Fenton WS, Hibbeln J, Knable M. 2000. Essential fatty acids, lipid membrane abnormalities, and the diagnosis and treatment of schizophrenia. Biol. Psychiatry 47, 8-21.

Fliesler SJ, Anderson RE. 1983. Chemistry and metabolism of lipids in the vertebrate retina. Prog. Lipid Res. 22, 79-131.

Frasure-Smith N, Lespérance F, Julien P. 2004. Major depression is associated with lower omega-3 fatty acid levels in patients with recent acute coronary syndromes. Biol. Psychiatry 55, 891-896.

Freeman MP, Hibblen J, Wisner K, Watchman M, Gelenberg AJ. 2006. An open trial of omega-3 fatty acids for depression in pregnancy. Acta Neuropsychiatr. 18, 21-24.

Freman M, Hibbblen J, Wisner K, Davis J, Mischoulon D, Peet M, Keck P, Marangell L, Richardson A, Lake J, Stoll A. 2006. Omega-3 fatty acids: evidence basis for treatment and future research in psychiatry. J. Clin. Psychiatry 67, 1954-1967.

Gerbi A, Maixent JM, Barbey O, Jamme I, Pierlovisi M. 1998. Alterations of $\mathrm{Na}, \mathrm{K}$-ATPase isoenzymes in the rat diabetic neuropathy: protective effect of dietary supplementation with n-3 fatty acids. J. Neurochem. 71, 732-740.

Green KN, Martínez-Coria H, Khashwji H-, Hall E, YurkoMauro K, Ellis L, LaFerla F. 2007. Dietary docosahexaenoic acid and docosapentaenoic acid ameliorate amyloid- $\beta$ and tau pathology via a mechanism involving presenilin 1 levels. J. Neuroscien. 27, 4385-4395.

Haag M. 2003. Essential fatty acids and the brain. Can. J. Psychiatry. 48, 195-203.

Hashimoto M, Hossain S, Agdul H, Shido O. 2005. Docosahexaenoic acid-induced amelioration on impairment of memory learning in amiloid $\beta$-infused rats relates to the decreases of amyloid $\beta$ and cholesterol levels in detergent-insoluble membrane fractions. Biochim. Biophys. Acta 1738, 91-98.

Hibbeln JR, Salem N. 1995. Dietary polyunsaturated fats and depression: when cholesterol alone doesn't satisfy. Am. J. Clin. Nutr. 62, 1-9.

Hirashima F, Parow AM, Stoll AL, Demopulos CM, Damico KE, Rohan ML, Espesen JG, Zuo CS, Cohen BM, Renshaw PF. 2004. Omega-3 fatty acid treatment and T2 whole brain relaxation time in bipolar disorder. Am. J. Psychiatry 161, 1922-1924.

Holman RT. 1998. The slow discovery of the importance of $\mathrm{w}-3$ essential fatty acids in human health. J. Nutr. 128, 427S-433S.

Holub BJ. 1978. Differential utilization of 1-palmitoyl and 1-stearoyl homologues of various unsaturated 1,2diacyl-sn-glycerols for phosphatidylcholine and phosphatidylethanolamine synthesis in rat liver microsomes. J. Biol. Chem. 253, 691-696.

Hong S, Gronert K, Devchand P, Moussignac RL, Serhan C. 2003. Novel docosatrienes and 17S-resolvins generated from docosahexaenoic acid in murine brain, human blood, and glial cells. J. Biol. Chem. 278, 14677-14687.

Horrobin DF, Glen Al, Vaddadi K. 1994. The membrane hypothesis of schizophrenia. Schizophr. Res. 13, 195207.

Hulbert AJ. 2003. Life, death and membrane bilayers. J. Exp. Biol. 206, 2303-2311.

Ikemoto A, Kobayashi T, Watanabe S, Okuyama H. 1997. Membrane fatty acid modifications of PC12 cells by arachidonate or docosahexaenoate affect neurite outgrowth but not norepinephrine release. Neurochem. Res. 22, 671-678.

Jeffrey B, Weisinger H, Neuronger M, Mitchell B. 2001. The role of docosahexaenoic acid in retinal function. Lipids 36, 859-871.

Kale A, Joshi S, Naphade N, Sapkale S, Raju M, Pillai A, Nasrallah H, Mahadik S. 2008. Opposite changes in predominantly docosahexaenoic acid (DHA) in cerebrospinal fluid and red blood cells from nevermedicated first-episode psychotic patients. Schizophr. Res. 98, 295-301.

Kang JX. 2005. Balance of omega-6/omega-3 essential fatty acids is important for health. World Rev. Nutr. Diet 95, 93-102.

Kim HY, Akbar M, Lau A, Edsall L. 2000. Inhibition of neuronal apoptosis by docosahexaenoic acid. J. Biol. Chem. 45, 35215-35223. 
Kim HY, Hamilton J. 2000. Accumulation of docosahexaenoic acid in phosphatidylserine is selectively inhibited by chronic ethanol exposure in C6 glioma cells. Lipids 3, 187-195.

Kim HY, Bigelow J, Kevala JH. 2004. Substrate preference in phosphatidylserine biosynthesis for docosahexaenoic acid containing species. Biochemistry 3, 1030-1036.

Kishida E, Yano M, Kasahara M, Masuzawa Y. 1998. Distinctive inhibitory activity of docosahexaenoic acid against sphingosine-induced apoptosis. Biochim. Biophys. Acta 1391, 401-408.

Kitajka K, Puskás L, Zvara A, Hackler L, Barceló-Coblijn G-, Yeo Y, Farkas T. 2002. The role of $\mathrm{n}-3$ polyunsaturated fatty acids in brain: Modulation of brain gene expression by dietary n-3 fatty acids. Proc. Natl. Acad. Sci. 99, 2619-2624.

Kin PY, Su KP. 2007. A meta-analytic review of doubleblind, placebo-controlled trials of antidepressant efficacy of omega-3 fatty acids. J. Clin. Psychiatry 68, 1056-1061.

Lengqvist J., Mata de Urquiza A, Bergman AC, Willson TM, Sjovall J. 2004. Polyunsaturated fatty acids including docosahexaenoic acid and arachidonic acid bind to retinoid $X$ receptor alpha ligand-binding domain. Mol. Cell. Proteomics 3, 692-703.

Lin PY, Su KP. 2007. A meta-analytic review of double blind, placebo-controlled trials of antidepressant efficacy of omega-3 fatty acids. J. Clin. Psychiatry 68, 1056-1061.

Locke CA, Stoll AL. 2001. Omega-3 fatty acids in major depression. World Rev. Nutr. Diet 89, 173-185.

Logan AC. 2003. Neurobehavioural aspects of omega-3 fatty acids: possible mechanism and therapeutic value in major depression. Altern. Med. Rev. 8, 410-425.

Logan AC. 2004. Omega-3 fatty acids and major depression: a primer for the mental health professional. Lipids Health Dis. 3, 25-31.

Lukiw W, Ciu J-G, Marcheselli V, Bodker M, Botkjaer A, Gotlinger K, Serhan C, Bazan N. 2005. A role of docosahexaenoic acid-derived neuroprotectin D1 in neural cell survival and Alzheimer disease. J. Clin. Invest. 115, 2774-2783.

Lukiw W, Bazan N. 2006. Survival signalling in Alzheimer's disease. Biochem. Soc. Trans. 34, 1277-1282.

Mamalakis G, Tornaritis M, Kafatos A. 2002. Depression and adipose essential polyunsaturated fatty acids. Prostaglandins Leukot. Essent. Fatty Acids. 67, 311318.

Marszalek JR, Kitidis C, Dirusso CC, Lodish HF. 2005. Long-chain acyl CoA synthetase 6 preferentially promotes DHA metabolism. J. Biol. Chem. 20, 1081710826.

Martin RE, Bazan NG. 1992. Changing fatty acids content of growth cone lipids prior to synaptogenesis. J. Neurochem. 59, 318-325.

Mata de Urquiza A, Liu S, Sjoberg M, Zetterstrom R, Griffiths W, Sjovall J, Perlman T. 2000. Docosahexaenoic acid, a ligand for the retinoid $X$ receptor in mouse brain. Science 290, 2140- 2144.

McCann J, Ames B. 2005. Is docosahexaenoic acid, an n3 long chain polyunsaturated fatty acid, required for development of normal brain function? An overview of evidence from cognitive and behavioral test in humans and animals. Am. J. Clin. Nutr. 82, 281-295.

Meltzer HY. 1990. Role of serotonin in depression. Ann. N. Y. Acad. Sci. 600, 486-499.

Moriguchi K, Yuri T, Yoshizawa K, Kiuchi K, Takada H. 2003. Dietary docosahexaenoic acid protects against-methyl-N-nitrosourea-induced retinal degeneration in rats. Exp. Eye Res. 77, 67-173.

Nagata S. 1997. Apoptosis by death factor. Cell 88, 355-365.

Nichizuka Y. 1995. Protein kinase $C$ and lipid signalling for sustained cellular responses. FASEB J. 9, 484-496.

Narayanan BA, Narayanan K, Eddy BS. 2001. Docosahexaenoic acid regulated genes and transcription factors inducing apoptosis in human colon cancer cells. Int. J. Oncol. 9, 1255-1262.

Niu SL, Mitchell, DC, Lim SY, Wen ZM, Kim HY. 2004. Reduced $G$ protein-coupled signalling efficiency in retinal rod outer segments in response to n-3 fatty acids deficiency. J. Biol. Chem. 279, 1098-1104.

Mozzi R, Buratta S, Goracci G. 2003. Metabolism and function of phosphatidylserine in mammalian brain. Neurochem. Res. 28, 195-214.

Peet M, Murphy B, Shay J, Horrobin DF. 1998. Depletion of omega-3 fatty acid levels in red blood cell membranes of depressive patients. Biol. Psychiatry 43, 315-319.

Prasad MR, Lowell MA, Yatin M, Dhillon H, Markesbery WR. 1998. Regional membrane phospholipids alteration in Alzheimer's disease. Neurochem. Res.23, 81-88.

Puskas LG, Kitajka K, Nyakas C, Barcelo-Coblijn G, Farkas T. 2003. Short-term administration of omega-3 fatty acids from fish oil results in increased transthyretin transcription in old rat hippocampus. Proc. Natl. Cad. Sci. USA. 100, 1580-1585.

Rapoport SI. 2001. In vivo fatty acid incorporation into brain phospholipids in relation to plasma availability, signal transduction and membrane remodelling. $J$. Mol. Neurosci. 16, 243-261.

Rojas CV, Martinez JI, Hoffman DR, Uauy R. 2003. Gene expression analysis in human fetal retinal explants treated with docosahexaenoic acid. Invest. Ophtalmol. Vis. Sci. 4, 3170-3177.

Rotstein NP, Aveldaño MI, Barrantes FJ, Roccamo AM, Politi LE. 1997. Apoptosis of retinal photoreceptors during development in vitro: protective effect of docosahexaenoic acid. J. Neurochem. 69, 504-513.

Salem N, Litman B, Kim HY. 2001. Mechanism of action of docosahexaenoic acid in the nervous system. Lipids 36, 945-959.

Sampath H, Ntambi JM. 2004. Polyunsaturated fatty acid regulation of gene expression. Nutr. Rev. 62, 333-339.

Sastry PS, Rao KS. 2000. Apoptosis and the nervous system. J. Neurochem. 74, 1-20.

Serhan C, Chiang N. 2004. Novel endogenous small molecules as the checkpoint controllers in inflammation and resolution. Rheum. Dis. Clin. North. Am. 30, 69-95.

Seung Kim HF, Weeber EJ, Sweatt JD, Stoll AL, Marangell LB. 2001. Inhibitory effects of omega-3 fatty acid on protein kinase $\mathrm{C}$ activity in vitro. Mol. Psychiatry 6, 246-248. 
Simopoulos AP. 2002. The importance of the ratio of omega-6/omega-3 essential fatty acids. Biomed. Pharmacother 56, 365-379.

Soderberg M, Edlund C, Kristensson K, Dallner F. 1991. Fatty acid composition of brain phospholipids in aging and in Alzheimer's disease. Lipids 26, 421-425.

Stahl LA, Begg DP, Weisinger RS, Sinclair AJ. 2008. The role of omega-3 fatty acids in mood disorders. Curr. Opin. Invest. Drugs 9, 57-64.

Teague WE, Fuller NL, Rand RP, Gawrisch K. 2002. Polyunsaturated lipids in membrane fusion events. Cell. Mol. Biol. Lett. 7, 262-264.

Uauy R, Valenzuela A. 2000. Marine oils: the health benefits of n-3 fatty acids. Nutrition 16, 680-684.

Valentine RC, Valentine DL. 2004. Omega-3 fatty acids in cellular membranes: a unified concept. Prog. Lipid Res. 43, 383-402.

Valenzuela A, Nieto S, Sanhueza J, Maymi P, Rojas I, Zañartu P. 2008. Supplementation of female rats with DHA-lysophosphatidylcholine increases DHA and acetylcholine content of the brain and improves the memory and learning capabilities of the pups. To be submitted.

Valenzuela A, Sanhueza J, Nieto S. 2006. Docosahexaenoic acid (DHA), essentiality and requirements: why and how to provide supplementation. Grasas y Aceites 57, 229-237.

Wadhwa PD, Sandman CA, Porto M, Dunkel-Schetter C, Garite TJ. 1993. The association between prenatal stress and infant birth weight and gestational age at birth: a prospective investigation. Am. J. Obstet. Gynecol. 169, 858-865.

Wainwright P. 2002. Dietary essential fatty acids and brain function: a developmental perspective on mechanism. Proc. Nutr. Soc. 61, 61-69.

Yao JK, Leonard S, Reddy R D. 2000. Membrane phospholipid abnormalities in post-mortem brains from schizophrenic patiens. Schizophr. Res. 42, 7-17.

Yehuda S, Rabinovits S, Carasso R L, Mostofsky DI. 1998. Fatty acids and brain peptides. Peptides 19, 407-419.

Recibido: 5/8/08 Aceptado: 1/10/08 